Acta Crystallographica Section E

Structure Reports

Online

ISSN 1600-5368

Ray J. Butcher, ${ }^{\mathrm{a} *}$ H. S. Yathirajan, ${ }^{b}$ H. G. Anilkumar, B. K. Sarojini ${ }^{c}$ and B. Narayana ${ }^{d}$

${ }^{a}$ Department of Chemistry, Howard University, 525 College Street NW, Washington, DC 20059, USA, 'bepartment of Studies in Chemistry, University of Mysore, Manasagangotri, Mysore 570 006, India, ' Department of Chemistry, P. A. College of Engineering, Nadupadavu, Mangalore 574 153, India, and ${ }^{d}$ Department of Chemistry, Mangalore University, Mangalagangotri 574 199, India

Correspondence e-mail:

raymond.butcher@nrl.navy.mil

\section{Key indicators}

Single-crystal X-ray study

$T=366 \mathrm{~K}$

Mean $\sigma(\mathrm{C}-\mathrm{C})=0.003 \AA$

$R$ factor $=0.024$

$w R$ factor $=0.054$

Data-to-parameter ratio $=22.0$

For details of how these key indicators were automatically derived from the article, see http://journals.iucr.org/e.

\title{
2-Bromo-1-(4-methylphenyl)-3-[4-(methyl- sulfanyl)phenyl]prop-2-en-1-one
}

The title compound, $\mathrm{C}_{17} \mathrm{H}_{15} \mathrm{BrOS}$, crystallizes in a noncentrosymmetric space group and shows significant nonlinear optical activity.

\section{Comment}

The present-day demand is for large and high quality ferroelectric, piezoelectric single crystals with minimum defects and inhomogenities. The important goal of crystal growth is the improvement of microscopic and macroscopic homogeneity, which is a necessity for any application. Different types of crystals being used are semiconductor crystals, oxide crystals, alkali halide crystals, and nonlinear optical (NLO) crystals. The NLO effect in organic molecules originates from a strong donor-acceptor intermolecular interaction, a delocalized $\pi$ electron system, and also the ability to crystallize in noncentrosymmetric space groups. Among several organic compounds reported for NLO properties, chalcone derivatives are notable materials for their excellent blue light transmittance and good crystallizability. They provide a necessary configuration to show an NLO property with two planar rings connected through a conjugated double bond (Goto et al., 1991; Uchida et al., 1998; Tam et al., 1989; Indira et al., 2002). Substitution on either of the phenyl rings greatly influences the non-centrosymmetric crystal packing (Butcher et al., 2006). It is speculated that, in order to improve activity, more bulky substituents should be introduced to increase the spontaneous polarization of a non-centrosymmetric crystal (Fichou et al., 1988). The molecular hyperpolarizability, $\beta$, is strongly influenced not only by the electronic effect, but also by the steric effect of the substituent (Cho et al., 1996). Bromo substituents can obviously improve the molecular first-order hyperpolarizabilities and can effectively reduce the dipoledipole interactions between the molecules (Zhao et al., 2002). $\alpha$-Bromochalcones are used to synthesize triazolothiadiazines which are found to be anticancer agents (Holla et al., 2001). Prompted by this, and in a continuation of our quest to synthesize newer materials which can find use in the photonics industry (Butcher et al., 2006), we have synthesized a new $\alpha$ bromochalcone and have found it to possess SHG efficiency. Its quantitative estimation is yet to be done. In view of the importance of the title compound, (I), the crystal structure is reported here.

The metrical parameters of (I) are similar to those observed in other chalcone derivatives (Butcher et al., 2006). The title compound crystallizes in the polar space group $P 2_{1}$ but contains no chiral centers. The source of the chirality of this compound lies in the fact that the two dissimilar rings are not coplanar. The two rings are significantly twisted with respect to each other [dihedral angle between ring planes is
Received 10 March 2006 Accepted 28 March 2006 
$\left.68.15(6)^{\circ}\right]$. There are also two weak intermolecular $\mathrm{C}-\mathrm{H} \cdots \mathrm{O}$ hydrogen bonds (Table 2) which contribute to the packing.<smiles>Cc1ccc(C(=O)/C(Br)=C/c2ccc(S(C)(C)C)cc2)cc1</smiles>

(I)

\section{Experimental}

A mixture of 2,3-dibromo-1-(4-methylphenyl)-3-[4-(methylsulfanyl)phenyl]propan-1-one $(0.42 \mathrm{~g}, 0.001 \mathrm{~mol})$ and triethylamine $(0.5 \mathrm{~g}$, $0.005 \mathrm{~mol})$ in dry benzene $(50 \mathrm{ml})$ was stirred for $24 \mathrm{~h}$. The precipitated triethylamine hydrochloride was removed by filtration. The filtrate was concentrated under reduced pressure and allowed to cool. The precipitated solid was filtered, dried and recrystallized from an acetone-toluene mixture (9:1) (yield: 85\%, m.p. $406 \mathrm{~K}$ ). Calculated for $\mathrm{C}_{17} \mathrm{H}_{15} \mathrm{BrOS}$; C 58.93, $\mathrm{H} 4.35 \%$; found C, 58.90, H, $4.35 \%$.

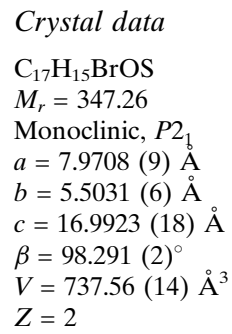

\section{Data collection}

Bruker SMART CCD area-detector diffractometer

$\varphi$ and $\omega$ scans

Absorption correction: multi-scan (SADABS; Sheldrick, 1996)

$T_{\min }=0.230, T_{\max }=0.482$

8184 measured reflections

\section{Refinement}

Refinement on $F^{2}$

$R\left[F^{2}>2 \sigma\left(F^{2}\right)\right]=0.024$

$w R\left(F^{2}\right)=0.055$

$S=0.95$

4028 reflections

183 parameters

$\mathrm{H}$-atom parameters constrained

\author{
$D_{x}=1.564 \mathrm{Mg} \mathrm{m}^{-3}$ \\ Mo $K \alpha$ radiation \\ Cell parameters from 6302 \\ reflections \\ $\theta=2.4-30.5^{\circ}$ \\ $\mu=2.92 \mathrm{~mm}^{-1}$ \\ $T=366$ (2) K \\ Chunk, colorless \\ $0.65 \times 0.30 \times 0.25 \mathrm{~mm}$
}

4028 independent reflections 3821 reflections with $I>2 \sigma(I)$

$R_{\text {int }}=0.022$

$\theta_{\text {max }}=30.8^{\circ}$

$h=-9 \rightarrow 11$

$k=-7 \rightarrow 7$

$l=-24 \rightarrow 24$

Table 1

Selected geometric parameters $\left(\AA,^{\circ}\right)$.

\begin{tabular}{llll}
\hline $\mathrm{Br}-\mathrm{C} 9$ & $1.889(2)$ & $\mathrm{C} 5-\mathrm{C} 8$ & $1.463(2)$ \\
$\mathrm{S}-\mathrm{C} 2$ & $1.7613(18)$ & $\mathrm{C} 8-\mathrm{C} 9$ & $1.344(2)$ \\
$\mathrm{S}-\mathrm{C} 1$ & $1.803(2)$ & $\mathrm{C} 9-\mathrm{C} 10$ & $1.502(3)$ \\
$\mathrm{O}-\mathrm{C} 10$ & $1.220(2)$ & $\mathrm{C} 10-\mathrm{C} 11$ & $1.489(3)$ \\
& & & \\
$\mathrm{C} 2-\mathrm{S}-\mathrm{C} 1$ & $102.45(9)$ & $\mathrm{O}-\mathrm{C} 10-\mathrm{C} 11$ & $121.15(17)$ \\
$\mathrm{C} 8-\mathrm{C} 9-\mathrm{Br}$ & $124.68(15)$ & $\mathrm{O}-\mathrm{C} 10-\mathrm{C} 9$ & $120.26(19)$ \\
$\mathrm{C} 10-\mathrm{C} 9-\mathrm{Br}$ & $113.62(13)$ & & \\
\hline
\end{tabular}

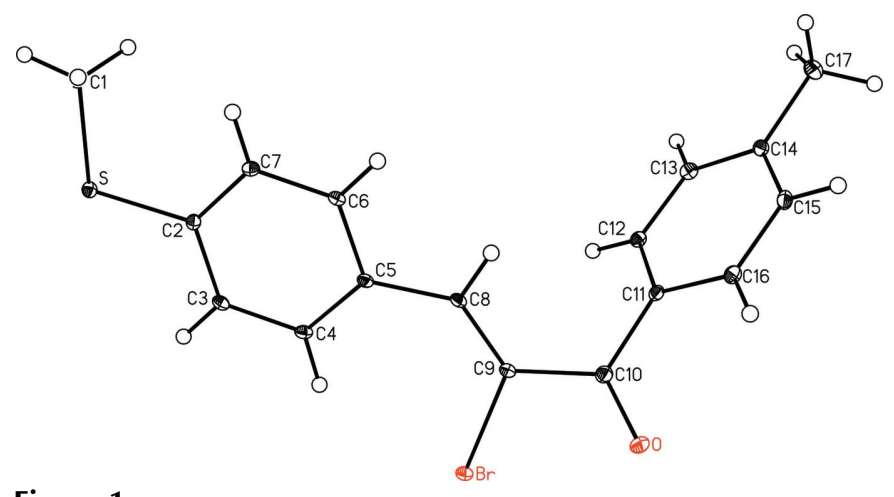

Figure 1

View of (I), showing the atom-numbering scheme. Displacement ellipsoids are drawn at the $50 \%$ probability level.

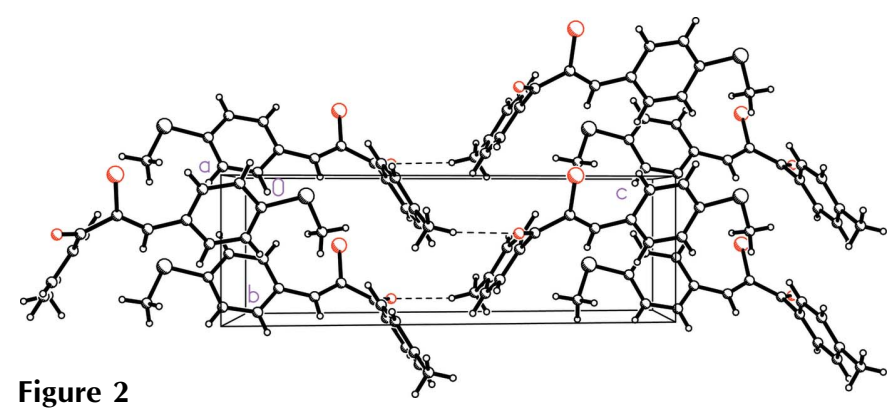

The molecular packing, viewed down the $c$ axis. Dashed lines indicate hydrogen bonds.

Table 2

Hydrogen-bond geometry $\left(\AA{ }^{\circ}\right)$.

\begin{tabular}{lllll}
\hline$D-\mathrm{H} \cdots A$ & $D-\mathrm{H}$ & $\mathrm{H} \cdots A$ & $D \cdots A$ & $D-\mathrm{H} \cdots A$ \\
\hline $\mathrm{C} 13-\mathrm{H} 13 A \cdots \mathrm{O}^{\mathrm{i}}$ & 0.93 & 2.51 & $3.392(2)$ & 159 \\
$\mathrm{C} 17-\mathrm{H} 17 B \cdots \mathrm{O}^{\mathrm{ii}}$ & 0.96 & 2.51 & $3.420(3)$ & 158 \\
\hline
\end{tabular}

Symmetry codes: (i) $x-1, y, z$; (ii) $-x+1, y+\frac{1}{2},-z+1$.

All $\mathrm{H}$ atoms were initially located in a difference Fourier map. The methyl $\mathrm{H}$ atoms were then constrained to an ideal geometry, with $\mathrm{C}-$ $\mathrm{H}$ distances of $0.98 \AA$ and $U_{\text {iso }}(\mathrm{H})=1.5 U_{\text {eq }}(\mathrm{C})$, but each group was allowed to rotate freely about its $\mathrm{C}-\mathrm{C}$ or $\mathrm{C}-\mathrm{S}$ bond. All other $\mathrm{H}$ atoms were placed in geometrically idealized positions and constrained to ride on their parent atoms, with $\mathrm{C}-\mathrm{H}$ distances in the range $0.95-1.00 \AA$ and with $U_{\text {iso }}(\mathrm{H})=1.2 U_{\text {eq }}(\mathrm{C})$. The highest electron-density peak is located $0.81 \AA$ from the $\mathrm{Br}$ atom.

Data collection: SMART (Bruker, 1998); cell refinement: SAINTPlus (Bruker, 1999); data reduction: SAINT-Plus; program(s) used to solve structure: SHELXS97 (Sheldrick, 1997); program(s) used to refine structure: SHELXL97 (Sheldrick, 1997); molecular graphics: SHELXTL (Bruker, 1999); software used to prepare material for publication: SHELXTL.

BKS thanks AICTE, Government of India, New Delhi, for financial assistance under the project Career Award for Young Teachers (CAYT) scheme and HGA thanks the University of Mysore for permission to carry out the research work.

\section{References}

Bruker (1998). SMART. Bruker AXS Inc., Madison, Wisconsin, USA Bruker (1999). SAINT-Plus and SHELXTL. Bruker AXS Inc., Madison, Wisconsin, USA. 


\section{organic papers}

Butcher, R. J., Yathirajan, H. S., Mithun, A., Narayana, B. \& Sarojini, B. K. (2006). Acta Cryst. E62, o1629-o1630.

Cho, B. R., Je, J. T., Kim, H. S., Jean, S. J., Song, O. K. \& Wang, C. H. (1996). Bull. Korean Chem. Soc. 17, 693-695.

Fichou, D., Watanabe, T., Takeda, T., Miyata, S., Goto, Y. \& Nakayama, M. (1988). Jpn J. Appl. Phy. 27, 429-430.

Flack, H. D. (1983). Acta Cryst. A39, 876-881.

Goto, Y., Hayashi, A., Kimura, Y. \& Nakayama, M. (1991). J. Cryst. Growth, 108, 688-698.

Holla, B. S., Sarojini, B. K., Rao, B. S., Akbarali, P. M., Kumari, N. S. \& Shetty, V. (2001). Il Farmaco, 56, 565-570.
Indira, J., Karat, P. P. \& Sarojini, B. K. (2002). J. Cryst. Growth, 242, 209214.

Sheldrick, G. M. (1996). SADABS. University of Göttingen, Germany.

Sheldrick, G. M. (1997). SHELXS97 and SHELXL97. University of Göttingen, Germany.

Tam, W., Guerin, B., Calabrese, J. C. \& Stevenson, S. H. (1989). Chem. Phys. Lett. 154, 93-96.

Uchida, T., Kozawa, K., Sakai, T., Aoki, M., Yoguchi, H., Abduryim, A. \& Watanabe, Y. (1998). Mol. Cryst. Liq. Cryst. 315, 135-140.

Zhao, B., Lu, W.-Q., Zhou, Z.-H. \& Wu, Y. (2002). J. Mater. Chem. 10, 15131517. 